\title{
Pharmacist Privilege in Saudi Arabia: Pharmacist Prescribing and Therapeutic Interchange
}

Faisal Al-Otaibi, Ph. D, Assistant Professor College of Pharmacy, Pharmacy Patrice Department, Shaqra University, Saudi Arabia. Mohamed Soliman Imam, Ph. D, Assistant Professor, Dean, College of Pharmacy, Shaqra University, Saudi Arabia.

Randa Mansour Abdel-Sattar Ahmed, Ph.D, Biomedical Science Department, College of Pharmacy, Shaqra University, Saudi Arabia.

Amsha Alotaibi, Pharm D, Clinical Pharmacist, College of Pharmacy, Pharmacy Patrice Department, Shaqra University, Riyadh, Saudi Arabia.

Asma Alotaibi, Pharm D, Clinical Pharmacist, College of Pharmacy, Pharmacy Practice Department, Shaqra University, Saudi Arabia. Amal Alotaibi, Pharm D, Clinical Pharmacist, College of Pharmacy, Shaqra University, Saudi Arabia.

Wesam Alsuwaid, Pharm D, Clinical Pharmacist, College of Pharmacy, Pharmacy Practice Department, Shaqra University, Saudi Arabia. Yousef Ahmed Alomi*, ID BSc. Pharm, MSc. Clin Pharm, BCPS, BCNSP, DiBA, CDE, Critical Care Clinical Pharmacists, TPN Clinical Pharmacist, Freelancer Business Planner, Content Editor and Data Analyst, Riyadh, Saudi Arabia.

\section{Correspondence:}

Dr. Yousef Ahmed Alomi, BSc. Pharm, MSc. Clin Pharm, BCPS, BCNSP, DiBA, CDE, Critical Care Clinical Pharmacists, TPN Clinical Pharmacist, Freelancer Business Planner, Content Editor and Data Analyst, P.O.BOX 100, Riyadh 11392, Riyadh, Saudi Arabia.

Phone no: +966504417712 E-mail: yalomi@gmail.com

Received: 11-10-2019;

Accepted: 13-12-2019

Copyright: (c) the author(s),publisher and licensee Pharmacology, Toxicology and Biomedical Reports. This is an open-access article distributed under the terms of the Creative Commons Attribution NonCommercial License, which permits unrestricted non-commercial use, distribution, and reproduction in any medium, provided the original work is properly cited.

This is an open access article distributed under the terms of the Creative Commons Attribution-NonCommercial-ShareAlike 4.0 License

Access this article online

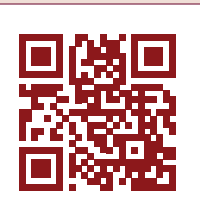

www.ptbreports.org

DOI:

10.5530/PTB.2020.6.9

\begin{abstract}
Objectives: To survey the pharmacist privilege in Saudi Arabia with an emphasis on pharmacist prescribing and therapeutic interchange. Methods: This is a 4-month cross-sectional survey of pharmacists privilege in Saudi Arabia. The study consists of two parts: the first part collects demographic information and the second part comprises 28 questions divided into four domains. These domains were derived from the previous literature and from the standards and regulations described by the American Society of Health-System Pharmacists (ASHP). The domains were privilege management and resources, pharmacist prescribing and therapeutic interchange, clinical and administration privilege, drug monitoring and healthcare education. We used 5-point Likert response scale system with closeand open-ended questions to obtain responses. The questionnaire was distributed in an electronic format to the director of pharmacy of various hospitals, deputy director, pharmacy quality management, clinical pharmacy coordinators, or any pharmacist assigned on behalf of hospital's director of pharmacy. The study discussed and analyzed pharmacist privilege in Saudi Arabia with an emphasis on pharmacist prescribing and therapeutic interchange. All data were obtained through the Survey Monkey system. Results: The survey was distributed to 36 hospitals. The pharmacist privilege of prescribing was available only at $12(32.14 \%)$ hospitals. over-the-counter (OTC) medications (19 $(90.48 \%)$ ) and vitamins (14 $(66.67 \%))$ were most of the medications with pharmacist privilege of prescribing followed by minerals $(11(52.38 \%))$ and electrolytes $(10(47.62 \%))$, whereas NSAIDs $(23(63.89 \%))$, Vitamins (19 $(52.78 \%))$, electrolytes $(17(47.22 \%))$ and antihistamine $(15(41.67 \%))$ were through therapeutic interchange program. Most of the pharmacists prescribing medication was through ambulatory care clinic $(19(52.78 \%))$ and when prescription was cosigned by the physician ( $19(52.78 \%))$. The average score of pharmacist privilege in the hospital's computerized physician order entry (CPOE) was 3.17 (63.46\%), whereas the average score of pharmacist privilege in the hospital's CPOE alerting system was 2.97 $(59.46 \%)$. Conclusion: In the Kingdom of Saudi Arabia, pharmacist privilege in prescribing medications is very low. Most of the medications prescribed by the pharmacist were OTC drugs. Thepharmacist privilege in the Computerized Physician Order Entry is not adequate. We highly recommend the implementation of a comprehensive pharmacist privilege system and regulations ed in Saudi Arabia.

Key words: Pharmacist, Privilege, Prescribing, Therapeutic, Interchange, Saudi Arabia.
\end{abstract}

\section{INTRODUCTION}

The profession of a pharmacist has developed over the past few years in the KSA. ${ }^{1}$ It has changed the role of a pharmacist from the distribution phase to the patients directed care. ${ }^{2}$ Recently, the privileges of a pharmacist has increased to provide services, including total parenteral nutrition, anticoagulant and pharmacokinetics services. $^{3-5}$ The pharmacy is active in prescribing medications, change orders and request laboratory tests for monitoring drug therapy. Pharmacists demonstrated excellent clinical outcomes and avoided unnecessary economic burden on the healthcare system. ${ }^{3,6}$ Multiple international studies have shown that pharmacists have the privilege of dependent or independent prescribing. ${ }^{7-9}$ Moreover, the pharmacist plays an active role as a prescriber and improves patient outcomes. ${ }^{10,11}$ Investigations related to the pharmacist privilege of prescribing are seldom in the Middle Eastern countries. ${ }^{5,12}$ The therapeutic intervention described the system of switching from patent to generic medications with the same chemical name or change from one drug to different drug names with the same therapeutic efficacy and safety and indications. ${ }^{13,14}$ Therapeutic interchange is a tool used to keep all medications available 24/7 for patients, improve drug therapy adherence to hospital formulary and avoid unnecessary economic burden on the healthcare services. Various studies have shown that the pharmacist has the privilege of a therapeutic interchange system..$^{11,13,15,16} \mathrm{It}$ could be an independent therapeutic interchange or one according to the approved guidelines of the pharmacy and therapeutic interchange system. Few studies have been conducted about pharmacist privilege with an emphasis on the therapeutic interchange system in Saudi Arabia or in Middle Eastern countries. ${ }^{5}$ In this study, we aimed to declare the pharmacist privilege with an emphasis on prescribing and therapeutic interchange in the kingdom of Saudi Arabia (KSA).

\section{METHODS}

This is a 4-month cross-sectional survey of prescribing privilege of pharmacists in the KSA. The study consisted of two parts: First parts collected demographic information and the second part comprised questionnaire with 28 questions divided into four domains. The domains were derived from the previous literature and American 
Society of Health-System Pharmacists (ASHP's standards and regulations. ${ }^{9,17-20}$ The domains were privilege management and resources, pharmacist prescribing and therapeutic interchange, clinical and administration privilege and drug monitoring and healthcare education. We used 5-point Likert response scale system with close-ended questions to obtain responses. The questionnaire was distributed in an electronic format and was distributed to the hospital director of pharmacy, deputy director and pharmacy quality management. The responders were followed-up via email and telephone after every 1-2 weeks. All primary healthcare centers, regional pharmacy administration at $\mathrm{MOH}$ were excluded from this study. This study discussed and analyzed the pharmacist privilege in Saudi Arabia with an emphasis on pharmacist prescribing and therapeutic interchange. All data were obtained through the Survey Monkey system and analyzed with the use of SPSS version 20 software. There were three methods of validation and more than two authors reviewed the survey independently. The pilot study was conducted and the survey data was corrected accordingly. Cronbach's alpha test for internal validity was analyzed. This survey was exempted from the international guidelines of IRB. ${ }^{21}$

\section{RESULTS}

The survey was distributed to 36 hospitals. Of them, $19.44 \%$ of the hospitals had 100-199 bed capacity; and had <50 bed capacity; while $13.89 \%$ of the hospitals had 50-99 bed capacity, 300-399 bed capacity and $\geq 600$ bed capacity each. Of the total 36 hospitals, 18 (50.00\%) hospitals were accredited by the CBAHI, 17 (47.22\%) hospitals were accredited by the Saudi Commission of Health Specialties and 13 (36.11\%) hospitals were accredited by the Joint Commission, whereas 5 (13.89\%) hospitals were not accredited by any organization and 13 (36.11\%) hospitals covered $50-74 \%$ of their patients by health insurance. Furthermore, 17 (47.22\%) responders were in the age group of 41-65 years. Most of the responders were Saudi nationals $(32(88.89 \%))$ (4 $(11.11 \%)$ responders were nonSaudi nationals). Most of the responders had obtained Diploma in Pharmacy (14 (38.89\%)) and Bachelor of Science in Pharmacy (12 (33.33\%)). Most of the responders had $<1$ year $(46.67 \%)$ of experience in pharmacy, whereas $30.77 \%$ of the responders had $4-6$ years of experience in clinical pharmacy and $43.75 \%$ had $>6$ years of experience in pharmacy administration (Tables 1 and 2). Furthermore, only 12 (32.14\%) hospitals had pharmacist privilege of prescribing. Most of the medications with pharmacist privilege of prescribing was for OTC medications (19 (90.48\%))

\begin{tabular}{|c|c|c|c|c|c|}
\hline Nationality & $\begin{array}{c}\text { Response } \\
\text { Count }\end{array}$ & $\begin{array}{c}\text { Response } \\
\text { Percent }\end{array}$ & No. of hospital Licensed Beds & $\begin{array}{c}\text { Response } \\
\text { Count }\end{array}$ & $\begin{array}{c}\text { Response } \\
\text { Percent }\end{array}$ \\
\hline Saudi & 32 & $88.89 \%$ & $<50$ & 7 & $19.44 \%$ \\
\hline Non-Saudi & 4 & $11.11 \%$ & $50-99$ & 5 & $13.89 \%$ \\
\hline Answered question & 36 & & 100-199 & 7 & $19.44 \%$ \\
\hline Skipped question & 0 & & 200-299 & 1 & $2.78 \%$ \\
\hline Age & $\begin{array}{c}\text { Response } \\
\text { Count }\end{array}$ & $\begin{array}{c}\text { Response } \\
\text { Percent }\end{array}$ & $300-399$ & 5 & $13.89 \%$ \\
\hline $20-30$ years & 2 & $5.56 \%$ & $400-499$ & 3 & $8.33 \%$ \\
\hline $31-40$ years & 16 & $44.44 \%$ & $=$ or $>600$ & 5 & $13.89 \%$ \\
\hline $41-65$ years & 17 & $47.22 \%$ & Medical City & 3 & $8.33 \%$ \\
\hline more than 65 years & 1 & $2.78 \%$ & Answered question & 36 & \\
\hline Answered question & 36 & & Skipped question & 0 & \\
\hline Skipped question & 0 & & The hospital accreditation & $\begin{array}{c}\text { Response } \\
\text { Count }\end{array}$ & $\begin{array}{c}\text { Response } \\
\text { Percent }\end{array}$ \\
\hline Academic qualifications & $\begin{array}{c}\text { Response } \\
\text { Count }\end{array}$ & $\begin{array}{c}\text { Response } \\
\text { Percent }\end{array}$ & CIBAHI & 18 & $50.00 \%$ \\
\hline Diploma Pharmacy & 3 & $8.33 \%$ & Joint Commotion USA & 13 & $36.11 \%$ \\
\hline Bsc. Pharm & 12 & $33.33 \%$ & Canada & 0 & $0.00 \%$ \\
\hline M.S & 2 & $5.56 \%$ & Saudi Council & 17 & $47.22 \%$ \\
\hline Msc. Clinical Pharmacy & 6 & $16.67 \%$ & None & 5 & $13.89 \%$ \\
\hline Pharm.D. & 14 & $38.89 \%$ & Answered question & 36 & \\
\hline Ph.D & 1 & $2.78 \%$ & Skipped question & 0 & \\
\hline MBA & 6 & $16.67 \%$ & $\begin{array}{l}\text { Total number of patients covered by } \\
\text { health insurance }\end{array}$ & $\begin{array}{l}\text { Response } \\
\text { Count }\end{array}$ & $\begin{array}{c}\text { Response } \\
\text { Percent }\end{array}$ \\
\hline Pharmacy Residency Two years (R1) & 2 & $5.56 \%$ & Non & 6 & $16.67 \%$ \\
\hline Pharmacy Residency one year (R2) & 0 & $0.00 \%$ & $<25 \%$ & 8 & $22.22 \%$ \\
\hline Fellowship & 1 & $2.78 \%$ & $25-49 \%$ & 6 & $16.67 \%$ \\
\hline Other (please specify) & 2 & $5.56 \%$ & $50-74 \%$ & 13 & $36.11 \%$ \\
\hline Answered question & 36 & & $75-100 \%$ of our patients. & 3 & $8.33 \%$ \\
\hline \multirow[t]{2}{*}{ Skipped question } & 0 & & Answered question & 36 & \\
\hline & & & Skipped question & 0 & \\
\hline
\end{tabular}




\begin{tabular}{|c|c|c|c|c|c|c|c|}
\hline Years of experience & Pharmacy Practice & Percent & $\begin{array}{l}\text { Clinical } \\
\text { Pharmacy }\end{array}$ & Percent & $\begin{array}{c}\text { Pharmacy } \\
\text { Administration }\end{array}$ & Percent & Response Count \\
\hline 0 & 4 & $30.77 \%$ & 4 & $30.77 \%$ & 5 & $38.46 \%$ & 13 \\
\hline$<1$ year & 7 & $46.67 \%$ & 4 & $26.67 \%$ & 4 & $26.67 \%$ & 15 \\
\hline $1-3$ & 9 & $39.13 \%$ & 6 & $26.09 \%$ & 8 & $34.78 \%$ & 23 \\
\hline $4-6$ & 7 & $26.92 \%$ & 8 & $30.77 \%$ & 11 & $42.31 \%$ & 26 \\
\hline Answered question & & & & & & & 36 \\
\hline Skipped question & & & & & & & 0 \\
\hline
\end{tabular}

and vitamins $(14(66.67 \%))$ followed by minerals $(11(52.38 \%))$ and electrolytes $(10(47.62 \%))$, whereas through therapeutic interchange program, most of the medications were having pharmacist prescribing privilege was for NSAIDs (23 (63.89\%)), vitamins (19 (52.78\%)), electrolytes $(17(47.22 \%))$ and for antihistamine $(15(41.67 \%))$ (Tables 3 and 4$)$. The pharmacist prescribes medication through ambulatory care clinic $(19(52.78 \%))$ and when prescription is cosigned by the physician (19 $(52.78 \%))$, followed by drugs under prescribing protocol (18 (50.00\%)) and pharmacokinetic consultation (18 (50.00\%)) (Table 5). The average score of pharmacist privilege in the hospital's Computerized Physician Order Entry (CPOE was 3.17 (63.46\%). Most pharmacy department with pharmacist privilege in prescribing belonged to outpatient pharmacy $(3.61(72.20 \%))$ followed by drug information $(3.39(67.8 \%))$ and prepackaging section $(3.14(67.80 \%))$ (Table 6). The average score of pharmacist prescribing privilege in the hospital's Computerized Physician Order Entry (CPOE alerting system was 2.97 (59.46\%). Most of the pharmacy department with pharmacist privilege in prescribing alerting system was for drug information $(3.31(66.2 \%))$ followed by outpatient pharmacy $(3.28(65.6 \%))$ and inpatient pharmacy $(3.14(62.80 \%))$ (Table 7).

\section{DISCUSSION}

The pharmacist privilege of prescribing was started in the 1990s when the clinical pharmacists were involved in providing TPN services with full independent prescribing of TPN order in hospital practice. ${ }^{4}$ While in the early 2000s, usually, the pharmacist had the complete authority of dispensing medications without prescription, which are called the OTC medications. The pharmacist was responsible for excellent clinical outcomes and considerable reductions in the cost of healthcare services. ${ }^{3}$ In addition, the therapeutic interchange system was started almost in the early 2000s during the group gulf medications purchases tenders. The pharmacist can switch automatically from providing patented drug to the generic drug of the same chemical name without the approval of a physician and perform fully independent therapeutic interchange. In this study, we focused on the privilege of pharmacists with an emphasis on prescribing and therapeutic interchange. We found that about onethird of the participants responded that they had a system similar to the previous studies $^{7,8}$ with some improvement from a previous local study. ${ }^{5}$ Our results were less than that of a previous study because of the lag time of system implementation at different countries. ${ }^{9}$ The pharmacist privilege in prescribing was more for OTC medications. Although the type of medication prescribed by the pharmacists were similar; however, this result differed from a previous study because the pharmacist privilege in prescribing was implemented at hospitals, whereas in this study, the pharmacist prescribing privilege was implemented at community pharmacies. ${ }^{8}$ Moreover, majority of the responders were working at private hospitals and they had implemented the OTC system within their pharmacies. Most of the medications that had the privilege of prescrib- ing were OTC, vitamins and minerals similar to a previous study, ${ }^{5}$ which represented the OTC drug list approved by the Saudi Food and Drug Authority. ${ }^{22}$ Majority of the medications used for therapeutic interchange were nonsteroidal anti-inflammatory drugs, vitamins and electrolytes similar to the previous study. ${ }^{5,16}$ All therapeutic interchange medications were available for the aforementioned medications and much easier to switch from one product to the other one. Most of the privileges of prescribing was countersigned by a physician, which is similar to the results of previous study. ${ }^{5}$ Our results were much better through prescribing protocol and at ambulatory clinics privileges and become resemble of previous study. ${ }^{5}$ The pharmacist to take an active role in the independent prescribing at ambulatory care clinics. Two-thirds of the responders had

\begin{tabular}{|c|c|c|}
\hline \multicolumn{3}{|c|}{$\begin{array}{l}\text { Pattern of the pharmacist have the privilege to write medication orders } \\
\text { or prescriptions }\end{array}$} \\
\hline Answer Choices & \multicolumn{2}{|c|}{ Responses } \\
\hline Yes & 12 & $32.14 \%$ \\
\hline No & 24 & $67.86 \%$ \\
\hline Answered & 36 & \\
\hline Skipped & 0 & \\
\hline \multicolumn{3}{|c|}{ The class of medication that you have privilege prescribing } \\
\hline Answer Options & $\begin{array}{l}\text { Response } \\
\text { Count }\end{array}$ & $\begin{array}{l}\text { Response } \\
\text { Percentages }\end{array}$ \\
\hline Aminoglycoside & 3 & $14.29 \%$ \\
\hline Antibiotics & 6 & $28.57 \%$ \\
\hline Anticoagulant & 8 & $38.10 \%$ \\
\hline OTC Medications & 19 & $90.48 \%$ \\
\hline Anti-Hypertensive & 4 & $19.05 \%$ \\
\hline Pain management medications & 3 & $14.29 \%$ \\
\hline Electrolytes & 10 & $47.62 \%$ \\
\hline Vitamins & 14 & $66.67 \%$ \\
\hline Minerals & 11 & $52.38 \%$ \\
\hline Thrombolytic & 2 & $9.52 \%$ \\
\hline Anti-depressions & 4 & $19.05 \%$ \\
\hline Anti-Psychotics & 1 & $4.76 \%$ \\
\hline Anti-convulsing & 2 & $9.52 \%$ \\
\hline $\begin{array}{l}\text { Other (most commonly prescribed } \\
\text { medication) }\end{array}$ & 2 & $9.52 \%$ \\
\hline Answered & 21 & \\
\hline Skipped & 15 & \\
\hline
\end{tabular}




\begin{tabular}{|l|c|c|}
\hline \multicolumn{3}{|l|}{$\begin{array}{l}\text { Table 4: The class of medication involved in therapeutic interchange } \\
\text { program with pharmacist privilege. }\end{array}$} \\
\hline Answer Options & $\begin{array}{c}\text { Response } \\
\text { Count }\end{array}$ & $\begin{array}{c}\text { Response } \\
\text { Percentages }\end{array}$ \\
\hline Antacid & 10 & $27.78 \%$ \\
\hline Vitamins & 19 & $52.78 \%$ \\
\hline Electrolytes & 17 & $47.22 \%$ \\
\hline Cephalosporin & 8 & $22.22 \%$ \\
\hline Laxatives & 10 & $27.78 \%$ \\
\hline Topical Corticosteroids & 7 & $19.44 \%$ \\
\hline NSAIDs & 23 & $63.89 \%$ \\
\hline Vaginal Antifungal & 3 & $8.33 \%$ \\
\hline Anti-Histamine & 15 & $41.67 \%$ \\
\hline OTC Drugs & 5 & $13.89 \%$ \\
\hline Non any medications & 4 & $11.11 \%$ \\
\hline Answered & 36 & \\
\hline Skipped & 0 & \\
\hline
\end{tabular}

Table 5: The type of method with prescribing privilege.

\begin{tabular}{|l|c|c|}
\hline \multicolumn{1}{|c|}{ Answer Options } & $\begin{array}{c}\text { Response } \\
\text { Count }\end{array}$ & $\begin{array}{c}\text { Response } \\
\text { Percentages }\end{array}$ \\
\hline Pharmacokinetic consultation & 18 & $50.00 \%$ \\
\hline $\begin{array}{l}\text { When prescription cosigned by } \\
\text { physician }\end{array}$ & 19 & $52.78 \%$ \\
\hline Drugs under prescribing protocol & 18 & $50.00 \%$ \\
\hline Medications Refill Clinic & 17 & $47.22 \%$ \\
\hline Ambulatory Care Clinic & 19 & $52.78 \%$ \\
\hline Supply and ostomy products & 10 & $27.78 \%$ \\
\hline Non & 3 & $8.33 \%$ \\
\hline Answered & 36 & \\
\hline Skipped & 0 & \\
\hline
\end{tabular}

\begin{tabular}{|c|c|c|c|c|c|c|c|c|}
\hline Answer Options & 1 & 2 & 3 & 4 & 5 & $\begin{array}{l}\text { Rating } \\
\text { Average }\end{array}$ & $\begin{array}{l}\text { Percent } \\
\text { Average }\end{array}$ & $\begin{array}{c}\text { Response } \\
\text { Count }\end{array}$ \\
\hline Inpatient pharmacy & 10 & 2 & 9 & 5 & 10 & 3.08 & 61.60 & 36 \\
\hline IV admixture Pharmacy & 8 & 3 & 10 & 6 & 9 & 3.14 & 62.80 & 36 \\
\hline Outpatient pharmacy & 5 & 2 & 8 & 8 & 13 & 3.61 & 72.20 & 36 \\
\hline Satellite pharmacy & 14 & 2 & 7 & 5 & 7 & 2.69 & 53.80 & 35 \\
\hline Emergency pharmacy & 10 & 4 & 7 & 5 & 10 & 3.03 & 60.60 & 36 \\
\hline Drug information & 6 & 2 & 12 & 4 & 12 & 3.39 & 67.80 & 36 \\
\hline Clinical Pharmacy & 8 & 2 & 10 & 4 & 12 & 3.28 & 65.60 & 36 \\
\hline Prepackaging section & 6 & 4 & 8 & 6 & 12 & 3.39 & 67.80 & 36 \\
\hline Pharmacy Store & 7 & 2 & 10 & 7 & 10 & 3.31 & 66.20 & 36 \\
\hline \multirow[t]{2}{*}{ Pharmacy home care } & 12 & 2 & 10 & 5 & 7 & 2.81 & 56.20 & 36 \\
\hline & & & & & & 3.17 & 63.46 & \\
\hline \multicolumn{6}{|l|}{ answered question } & & & 36 \\
\hline \multicolumn{6}{|l|}{ skipped question } & & & 0 \\
\hline \multicolumn{9}{|c|}{$\begin{array}{l}\text { 1-No activity to implement 2-Discussed for possible implementation in the pharmacy but is not implemented at this time } \\
\text { 3-Partially implemented for some or all patients, prescriptions, drugs, or hospital department } \\
\text { 4-Fully implemented for some patients, prescriptions, drugs, or hospital departments } \\
\text { 5-Fully implemented for ALL patients, prescriptions, drugs, or hospital departments }\end{array}$} \\
\hline
\end{tabular}

the privilege of prescribing during CPOE with an emphasis on ambulatory care clinic and drug information services. This is because OTC medications are easy to prescribe and implementation of the drug information service including the formulary guidelines. ${ }^{11}$ The pharmacists privilege of prescribing during therapeutic interchange demands certain guidelines and pharmacy law to standardize the policies and procedures between the two systems in the kingdom of Saudi Arabia (KSA).

\section{CONCLUSION}

The pharmacist have prescribing privilege and therapeutic interchange utilization in the KSA. The pharmacist plays an active role in prescribing or perform therapeutic interchange of OTC medications through pharmacy law. The electronic entry of pharmacist privilege has not reach its optimal level. Full implementation of the comprehensive pharmacist privilege system and regulations through in-depth guidelines about prescribing and therapeutic interchange is highly recommended in the KSA.

\section{ACKNOWLEDGEMENT}

None.

\section{CONFLICT OF INTEREST}

The authors declare no conflict of interest. 


\begin{tabular}{|c|c|c|c|c|c|c|c|c|}
\hline Answer Options & 1 & 2 & 3 & 4 & 5 & $\begin{array}{c}\text { Rating } \\
\text { Average }\end{array}$ & $\begin{array}{l}\text { Percent } \\
\text { Average }\end{array}$ & $\begin{array}{c}\text { Response } \\
\text { Count }\end{array}$ \\
\hline Inpatient pharmacy & 8 & 3 & 10 & 6 & 9 & 3.14 & 62.80 & 36 \\
\hline IV admixture Pharmacy & 11 & 3 & 6 & 7 & 9 & 3.00 & 60.00 & 36 \\
\hline Outpatient pharmacy & 7 & 2 & 12 & 4 & 11 & 3.28 & 65.60 & 36 \\
\hline Satellite pharmacy & 15 & 3 & 7 & 2 & 9 & 2.64 & 52.80 & 36 \\
\hline Emergency pharmacy & 11 & 4 & 9 & 3 & 9 & 2.86 & 57.20 & 36 \\
\hline Drug information & 8 & 3 & 7 & 4 & 13 & 3.31 & 66.20 & 35 \\
\hline Clinical Pharmacy & 11 & 2 & 10 & 4 & 9 & 2.94 & 58.80 & 36 \\
\hline Prepackaging section & 11 & 3 & 10 & 3 & 9 & 2.89 & 57.80 & 36 \\
\hline Pharmacy Store & 9 & 2 & 10 & 4 & 11 & 3.17 & 63.40 & 36 \\
\hline Pharmacy home care & 15 & 3 & 9 & 3 & 6 & 2.50 & 50.00 & 36 \\
\hline Average & & & & & & 2.97 & 59.46 & \\
\hline \multicolumn{6}{|l|}{ answered question } & & & 36 \\
\hline \multicolumn{6}{|l|}{ skipped question } & & & 0 \\
\hline \multicolumn{9}{|c|}{$\begin{array}{l}\text { 1-No activity to implement 2-Discussed for possible implementation in the pharmacy but is not } \\
\text { 3-Partially implemented for some or all patients, prescriptions, drugs, or hospital department } \\
\text { 4-Fully implemented for some patients, prescriptions, drugs, or hospital departments } \\
\text { 5-Fully implemented for ALL patients, prescriptions, drugs, or hospital departments }\end{array}$} \\
\hline
\end{tabular}

\section{ABBREVIATIONS}

MOH: Ministry of Health; KSA: Kingdom of Saudi Arabia; CBAHI: Saudi Central Board for Healthcare Accreditation; ASHP: American Society of Health-System Pharmacists; SPSS: Statistical Package of Social Sciences; CPOE: Computerized Physician Order Entry; OTC: over the counter; TPN: total parenteral nutrition.

\section{REFERENCES}

1. Alomi YA, Alghamdi SJ, Alattyh RA. History and Strategies of Drug Information Services at Ministry of Health in Saudi Arabia. Pharmacol Toxicol Biomed Reports. 2019;5(1):1-3.

2. Asiri YA. Emerging frontiers of pharmacy education in Saudi Arabia: The metamorphosis in the last fifty years. Saudi Pharm J. 2011;19(1):1-8.

3. Alomi1 YA, Fallatah AO, Al-Shubaar N, Qohal AA, Alameer LY. The Clinical Outcomes of Pharmacist Interventions in Total Parenteral Nutrition services in Riyadh City, Saudi Arabia. Int J Pharm Heal Sci. 2019;2(2):135-40

4. Alomi YA, Aljudaibi SM, Alghamd SJ. National Survey of Total Parenteral Nutrition Practice in Saudi Arabia: Prescribing and Transcribing at MOH Hospitals. EC Nutr. 2016;4(1):795-803

5. Alomi YA, Alghamdi SJ, Alattyh RA, Shorog E, Alshahran A, Alasmary S, et al. National Survey of Pharmacy Practice At Ministry of Health Hospitals in Saudi Arabia 2016-2017: Prescribing and Medication Management. J Pharm Pr Community Med. 2018;(5):S54-9.

6. Alomi YA, Fallatah AO, Bahadig FA, Qahtani AAAL. The Economic Outcomes of Pharmacist Interventions in Total Parenteral Nutrition Services in Saudi Arabia. Pharmacol Toxicol Biomed Reports. 2019;5(3s):S40-9.

7. Pedersen CA, Schneider PJ, Scheckelhoff DJ. ASHP national survey of pharmacy practice in hospital settings: Prescribing and transcribing: 2013. Am J Heal Pharm. 2014;71(11):924-42.

8. Pedersen CA, Schneider PJ, Scheckelhoff DJ. ASHP national survey of pharmacy practice in hospital settings: Prescribing and transcribing: 2016. American Journal of Health-System Pharmacy. 2017;74(17):1336-52.

9. Guirguis LM, Hughes CA, Makowsky MJ, Sadowski CA, Schindel TJ, Yuksel $\mathrm{N}$. Survey of pharmacist prescribing practices in Alberta. Am J Heal Pharm.
2017:74(2):62-9

10. Tsuyuki RT, Houle SKD, Charrois TL, Kolber MR, Rosenthal MM, Lewanczuk $R$, et al. Randomized Trial of the Effect of Pharmacist Prescribing on Improving Blood Pressure in the Community. Circulation. 2015;132(2):93-100.

11. Kang A, Thompson A, Rau J, Pollock A. Effects of clinical decision support and pharmacist prescribing authority on a therapeutic interchange program. Am J Heal Pharm. 2018;75(17S):S72-6.

12. Alomi YA, Alghamdi SJ, Alattyh RA. National Survey of Pharmacy Practice at $\mathrm{MOH}$ Hospitals in Saudi Arabia 2016-2017 : Clinical Pharmacy Services. J Pharm Pr Community Med. 2018;4(1s):1S-8S.

13. Oh T, Franko TG. Comprehensive therapeutic interchange program in a community hospital. Am J Hosp Pharm. 1991;48(7):1471-7.

14. Carroll NV. Formularies and therapeutic interchange: The health care setting makes a difference. Am J Heal Pharm. 1999;56(5):467-72

15. Carroll NV. Therapeutic interchange in community pharmacies in Virginia. Am J Heal Pharm. 2000;57(9):882-6.

16. Schachtner JM, Guharoy R, Medicis JJ, Newman N, Speizer R. Prevalence and cost savings of therapeutic interchange among U.S. hospitals. Am J Heal Pharm. 2002;59(6):529-33.

17. Burns AL. Credentialing and Privileging of Pharmacists: A Resource Paper from the Council on Credentialing in Pharmacy Council. Consult Pharm. 2015;29(11):757-70

18. Jordan TA, Hennenfent JA, Lewin JJ, Nesbit TW, Weber R. Elevating pharmacists' scope of practice through a health-system clinical privileging process. Am J Heal Pharm. 2016;73(18):1395-405.

19. Blair MM, Carmichael J, Young E, Thrasher K. Pharmacist privileging in a health system: Report of the Qualified Provider Model Ad Hoc Committee. Am J Heal Pharm. 2007;64(22):2373-81.

20. Christel G. Svingen. Clinical Pharmacist Credentialing and Privileging: A Process for Ensuring High-Quality Patient Care. Parctioner Forum. 2019;36(4):155-7.

21. The Office for Human Research Protections. Human Subject Regulations Decision Charts. Chart. 2016. [cited 2019 Nov 4]. Available from: https://www.hhs. gov/ohrp/regulations-and-policy/decision-charts/index.htm

22. Saudi Food and Drug Authority. List of human medicine and herbal health. Herbal and Drugs. 2019. [cited 2019 Jun 17]. Available from: https://www.sfda.gov. sa/en/drug/resources/Pages/DrugsUnderRegistrations.aspx 